Check for updates

Cite this: RSC Adv., 2018, 8, 14864

Received 31st October 2017

Accepted 4th March 2018

DOI: $10.1039 / c 7 r a 11966 f$

rsc.li/rsc-advances

\title{
Fabrication of air-stable, transparent Cu grid electrodes by etching through a PVA-based protecting layer patterned using a screen mesh $\uparrow$
}

\author{
H. Tokuhisa, D* S. Tsukamoto, T. Nobeshima and N. Yamamoto
}

As an alternative to conventional indium-tin-oxide (ITO) electrodes, a transparent Cu grid electrode was fabricated by etching a sputtered $\mathrm{Cu}$ on a flexible polyethylene naphthalate film through a polyvinyl alcohol (PVA)-based protecting layer. The masking pattern of the PVA-based polymer on the Cu was generated by evaporation of an aqueous solution containing PVA-based polymers using a screen mesh as a template. The solution formed a stable liquid-bridge network between contact points of the screen mesh and the substrate after being dropped onto the mesh placed on the substrate. Drying of the solution yielded grid or dotted patterns, depending on the concentration of PVA. Etching of the Cu film covered with the PVA pattern was done with a $\mathrm{FeCl}_{3}$ methanolic solution to form a grid-patterned $\mathrm{Cu}$ electrode. Although some underetching was observed, adjusting the etching time gave a fine line network of $\mathrm{Cu}$ with the PVA coated thoroughly. The $\mathrm{Cu}$ grid electrode showed a transparency of $87.2 \pm$ $5.2 \%$ at $550 \mathrm{~nm}$ and $6.1 \pm 5.3 \Omega \square^{-1}$, which is comparable to or greater than that of the conventional ITO. Furthermore, we found that the PVA coating barrier significantly enhanced the oxidation resistance of the Cu grid electrode.

\section{Introduction}

Transparent electrodes have been widely used in applications varying from solar cells ${ }^{1,2}$ to light emitting diodes, ${ }^{3,4}$ displays, ${ }^{5,6}$ and touch-panels. ${ }^{7,8}$ One of the most commonly used materials is indium-doped tin oxide (ITO), because it can simultaneously deliver a low resistance $\left(\sim 10 \Omega \square^{-1}\right.$ on glass substrates) and a high transparency $(>83 \%)$. However, its fragility, scarcity of indium, and expensive processing limit its use in emerging devices such as wearable electronics, flexible solar cells, and flexible displays. ${ }^{9-11}$ Furthermore, the enlargement of touch panels demands much lower resistance than that of the conventionally used ITO. Thus, many researchers have attempted to develop alternative materials and methods to replace ITO. One of the promising methods is transparent film formation using metals with inherently low resistivity, such as $\mathrm{Ag}, \mathrm{Au}$, and $\mathrm{Cu}^{12-18}$ in the form of light percolation electrodes. These include solution-processed metal networking consisting of metal nanowires, "an additive method,",,12,19 and patterned metal networking from evaporated metal sources, "a subtractive method" ${ }^{\text {20-22 }}$ Building-up methods such as the former require a good dispersibility of metal nanowires and good contact between them. However, the use of $\mathrm{Cu}$, which has attracted

Flexible Electronics Research Center, National Institute of Advanced Industrial Science and Technology, Tsukuba, Ibaraki, Japan.E-mail: h-tokuhisa@aist.go.jp

$\dagger$ Electronic supplementary information (ESI) available. See DOI: 10.1039/c7ra11966f much attention because of its low cost, abundance, and high electromigration resistance, ${ }^{23,24}$ is often hampered by difficulties owing to its ease of oxidation. A solution to this problem is the use of a subtractive process, in which a protective pattern is formed on a high-quality thin $\mathrm{Cu}$ film prior to pattern etching, because the remaining $\mathrm{Cu}$ structure can maintain the bulk resistivity even after etching.

Photolithography is a well-developed technique to form protecting patterns for etching, but it involves many expensive process steps, thereby losing the advantage over ITO. There are some reports of transparent $\mathrm{Cu}$ electrode formation by etching without the use of photolithography techniques. For example, electrospun nanofibers of polyacrylonitrile were formed before etching, causing the deposition of randomly overlapped line patterns of the polymer over a Cu surface. ${ }^{22}$ Double evaporative assemblies involving flow-coating to form a polymer line pattern with a $90^{\circ}$ rotation yielded a grid pattern of polystyrene as a protecting layer. ${ }^{21}$

We herein demonstrate another simple method to form a grid type pattern of a polyvinyl alcohol (PVA)-based polymer on a thin $\mathrm{Cu}$ film using a screen mask as a template. A droplet of a dilute polymer solution was spread over the screen mask, which was placed on a $\mathrm{Cu}$ film and dried. During the drying process, the solution moved along the framework of the mask. Even at the final stage of drying, the solution could maintain the structure, resulting in a solidified grid pattern of the polymer on the $\mathrm{Cu}$ surface. The following $\mathrm{Cu}$ etching gave a $\mathrm{Cu}$ grid electrode with the linewidth of $3 \mu \mathrm{m}$, showing low resistivity and 
high transmittance. In addition, we found that the left PVA patterns on the etched $\mathrm{Cu}$ film could serve as an oxidation resistive layer, because they completely covered the $\mathrm{Cu}$.

\section{Experimental section}

\section{Materials}

PVA (molecular weight 1500) and iron(III) chloride (97\%) were purchased from Sigma-Aldrich. E201, a colorless extender including 10-14\% water-soluble acrylic polymer, was purchased from HOLBEIN Works, Ltd., Japan. All materials were used as received. A thin $\mathrm{Cu}$ film $(1 \mu \mathrm{m})$ on a polyethylene naphthalate (PEN, $120 \mu \mathrm{m}$ ) film (Panac Co., Ltd., Japan) was prepared using a DC magnetron sputtering system (Shibaura Mechatronics, CFS4EP-LL, i-miller) in an Ar atmosphere under a pressure of $0.5 \mathrm{~Pa}$. An $\mathrm{Al}_{2} \mathrm{O}_{3}$ adhesion layer with a thickness of $5 \mathrm{~nm}$ was sputtered prior to $\mathrm{Cu}$ deposition in an $\mathrm{Ar}$ and $\mathrm{O}_{2}$ mixed gas ( $95: 5$ ) under a pressure of $0.5 \mathrm{~Pa}$. The $\mathrm{Cu}$ films were used without further treatment or washed with an alkali-based solution (50 $\mathrm{mg} \mathrm{mL}^{-1}$ ) using C-4000 (Asahi Cleaner, Japan) at $60{ }^{\circ} \mathrm{C}$ for $3 \mathrm{~min}$, which is often used as a degreasing agent before an electroplating process. Silk-screen printing plates with plainwoven fabric stainless screens of 325 and 500 lines per inch with thread diameters of 23 and $19 \mu \mathrm{m}$, respectively, were purchased from Murakami Co. Ltd., Japan.

\section{Fabrication of PVA grid-patterned surfaces}

The glass substrates and screen meshes were washed with acetone, ethanol, and distilled water under sonication, followed by drying with air flowing. PVA-based solutions were prepared as follows: first, an appropriate amount of PVA was mixed with water; second, an extender (E201) containing 10-14\% of acrylic resin was diluted with water to produce a $1 \mathrm{wt} \%$ solution; third, they are mixed in a $1: 1$ ratio to obtain $0.05,0.5$, and 5 wt\% PVA solutions with (5-7) $\times 10^{-4}$ wt $\%$ acrylic resin. A silk-screen printing plate was placed over a substrate. Then, $15 \mu \mathrm{L}$ of the solution was dropped on the screen mask and spread over a $2 \mathrm{~cm} \times 2 \mathrm{~cm}$ glass or Cu/PEN film. It was dried at room temperature, typically for $1 \mathrm{~h}$. Finally, the substrates were manually detached from the masks.

\section{Etching of Cu film}

For $\mathrm{Cu}$ etching, $\mathrm{FeCl}_{3}$ (Sigma-Aldrich, USA) and methanol (Wako, Japan) were mixed to obtain $22 \mathrm{mmol} \mathrm{L}^{-1}$ of the $\mathrm{FeCl}_{3}$ etchant. The PVA-patterned surfaces on a sputtered $\mathrm{Cu} / \mathrm{PEN}$ film were immersed for 5-6 min in the etchant under gentle stirring, followed by washing with methanol, and drying with $\mathrm{N}_{2}$.

\section{Characterization}

Scanning electron microscopy (SEM) images were obtained on a JSM-7400F scanning electron microscope (JEOL, Japan) at 10 $\mathrm{kV}$. The samples were coated with a thin Pt layer before observation. The pattern heights were measured using a stylus surface profiler, Dektak XT-(ULVAC, Japan). Optical images of the surfaces were taken using a VW-9000/VW-600c digital microscope (KEYENCE, Japan). The optical transmittance of the $\mathrm{Cu}$ grid electrodes was measured using a UV-vis spectrometer, UV-3100PC (SHIMADZU, Japan); a baseline correction was performed using the bare PEN substrate, which was also used as a reference. For sheet resistance measurements, Au electrode pads with a gap distance of $5 \mathrm{~mm}$ were modified on the $\mathrm{Cu}$ grid electrodes by a simple sputtering deposition before the measurements. The sheet resistance of the $\mathrm{Cu}$ grid electrodes was measured by the four-probe method using a KB-100 (KB-esi, Germany). More than three measurements were performed for each sample, and the results were averaged. As for evaluation as a capacitor sensor, the sensor was fabricated by putting two grid electrodes together in a face to face manner as shown in the inset of Fig. 7. Capacitance data of the sensor was collected by a precision LCR meter, 4284 A (Agilent Technologies, USA) when pressure was added by an autograph, AGS-X (Shimadzu Corporation, Japan).

\section{Results and discussion}

\section{Grid pattern formation of PVA on a glass substrate using screen mesh templates}

Aqueous solutions of $0.5 \mathrm{wt} \%$ PVA containing $(5-7) \times 10^{-4} \mathrm{wt} \%$ acrylic resin (PVA-based solution) were dropped over a 500count screen mesh on a hydrophilic glass substrate and dried for $1 \mathrm{~h}$ at room temperature. The role of the acrylic resin additive is explained later. The removal of the mesh yielded a grid pattern of the polymer, as shown in Fig. 1(a). It was a grid line with a width of $3 \mu \mathrm{m}$ and a height of $2.5 \mu \mathrm{m}$, with a diamond-shaped pattern at every other crossing point. The pattern formation mechanism is essentially the same as in
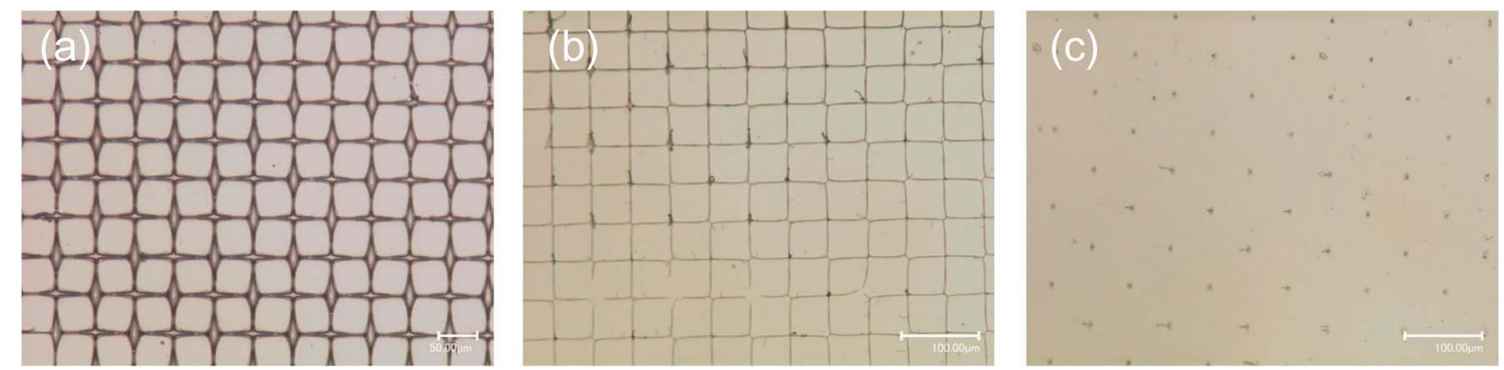

Fig. 1 Optical microscopy images of PVA-based polymers on a glass fabricated through a screen mesh using aqueous solutions containing different concentrations of PVA: (a) $0.5 \mathrm{wt} \%$, (b) $0.05 \mathrm{wt} \%$, and (c) $0.005 \mathrm{wt} \%$. 
a previous report, ${ }^{25}$ where a hydrophobic polymer was deposited on a glass substrate using a screen mesh. First, a drop of solution could penetrate along the mesh wire frame via capillary action (Fig. 2(1)). Then, evaporation of the solvent collects the concentrated solution at the contact points between the screen mesh and the glass surface, forming pendular rings together with liquid bridges between the neighbors (Fig. 2(2)). As the drying proceeds further, the polymer is solidified, which depends on the concentration and reflects the drying history (Fig. 2(3)). When the solution was diluted 10 times with water, a grid pattern with a narrower line of $1 \mu \mathrm{m}$ was obtained (Fig. 1(b)). This indicates that although the solution movement could be the same as that described earlier, the polymer should be solidified at the final stage, where liquid bridges were nearly breaking because of the lower initial concentration. The narrow linewidth suggests that the liquid bridge could be stable, even at the final stage of the drying. This may be because PVA can serve as a surfactant to stabilize the interface, similar to a soap bubble, to prevent rupture even at the final stage of drying. ${ }^{26}$ A further 10 times dilution gave only dotted patterns without linking the lines (Fig. 1(c)). This means that eventually, the liquid was collected at the contact point of the mesh on the glass after the liquid bridges were broken, which is in a good agreement with our previous observation. ${ }^{25}$ When no acrylic resin was mixed, part of the diamond pattern was torn off the glass. Because the dried PVA was brittle due to its crystallinity, the contact point of the mesh on the glass where a strong force was applied was broken. The acrylic resin additive can work as an inhibiter for crystallization. In addition, we think that the additive can partially promote cross-

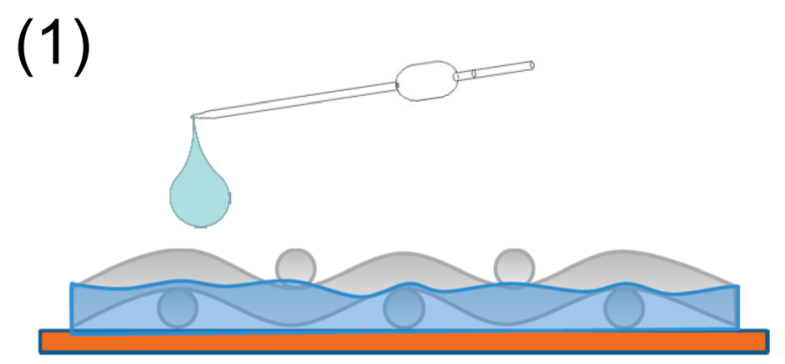

(2)
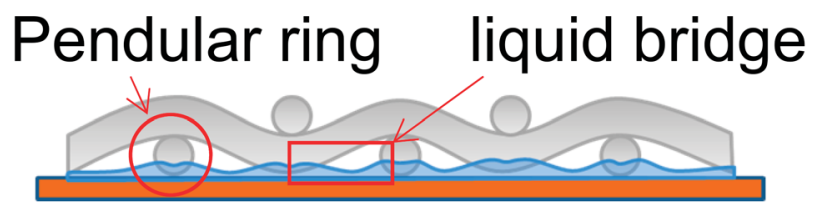

(3) Patterned PVA

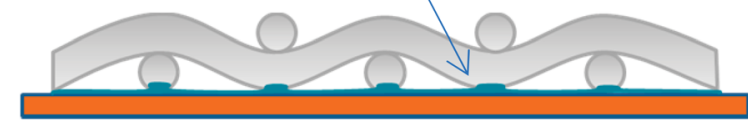

Fig. 2 Schematic viewgraphs of a possible mechanism for the PVA pattern formation through a screen mesh. linking of the PVA, thereby making it more difficult to wash away with $\mathrm{H}_{2} \mathrm{O}$. Indeed, the partial PVA cross-linking was confirmed by a gel permeation chromatography analysis to compare the molecular weight distributions before and after the addition of the acrylic resin into the PVA solution (Fig. 1S†).

\section{Grid pattern formation of PVA on a sputtered $\mathrm{Cu}$ film}

We then attempted to form the grid polymer pattern on a $\mathrm{Cu}$ sputtered film on a PEN substrate using a $0.5 \mathrm{wt} \%$ PVA-based solution, which gave a narrow, stable grid line on the glass. However, after removal of the screen mesh, the cross points of the polymer pattern, which could bind between the substrate and the screen mesh, disappeared (Fig. 3(a)). We thought that this was because of the difference between the surface properties of the $\mathrm{Cu}$ and glass substrates. Indeed, the contact angles were different between them. The cleaned glass substrate had a contact angle of $<20^{\circ}$, whereas that for the as sputtered $\mathrm{Cu}$ surface was approximately $60^{\circ}$, probably owing to contaminations from the air. Therefore, the $\mathrm{Cu}$ surface was exposed to an alkali based solution containing a surfactant to remove them, resulting in a contact angle of $<20^{\circ}$. The surfactant can also form a self-assembled layer on top of the cleaned $\mathrm{Cu}$ surface to enhance the wettability. The treatment worked quite well, yielding a grid pattern with a large area without significant defects, as shown in Fig. 3(b). This indicates that the adhesiveness of the PVA-based polymer patterns might be related to the surface hydrophilicity. Fig. 4(a)-(c) show SEM images of a PVA pattern on a Cu/PEN film. Essentially, the pattern is almost the same as that on a glass, as shown above. Examining the lines more closely, the difference in contrast between the PVA and the $\mathrm{Cu}$ surface in the SEM images could provide information about the structure. The PVA line fabricated through the liquid bridges between pendular rings as shown in Fig. 4(c) can be separated into two components: (1) a tubeshaped structure with a width of $0.25 \mu \mathrm{m}$ in the middle and (2) a thin layer like bleeding extended approximately $1.75 \mu \mathrm{m}$ from the edge of the tube at both sides (indicated by arrows in the figure). This suggested that the liquid bride maintained a homogeneous, stable line even after the solution reached the concentration where the PVA came out. This can be partially explained by the slow evaporation of water during drying, so as to give the polymer sufficient time to diffuse into the interior of the liquid line. ${ }^{27}$
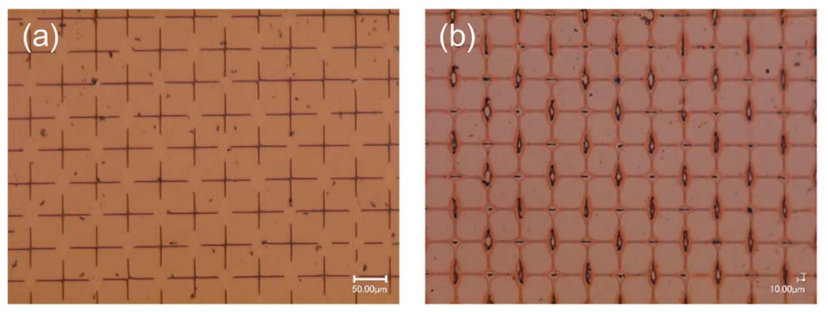

Fig. 3 Optical microscopy images of PVA-based polymers on $\mathrm{Cu}$ sputtered PEN film fabricated through a screen mesh using aqueous solutions containing 0.5 wt\% of PVA, (a) without and (b) with the $\mathrm{Cu}$ surface cleaning. 


\section{$\mathrm{Cu}$ etching with $\mathrm{FeCl}_{3}$}

For $\mathrm{Cu}$ etching, the $\mathrm{Cu}$ film with a PVA-grid pattern deposited was dipped into the $\mathrm{Cu}$ etchant comprising $0.01 \mathrm{M} \mathrm{FeCl}_{3}$ methanolic solution, at room temperature. We used methanol instead of the more commonly used water as the solvent, because water would remove the PVA patterning from the surface, resulting in no $\mathrm{Cu}$ pattern left after etching. The etching time was 5-6 min to obtain transparent grid electrodes. This wet etching of $\mathrm{Cu}$ could proceed isotropically because the etchant was only gently stirred, so that the mass transportation of $\mathrm{Fe}^{3+}$ relied on the random diffusion in the vicinity of the $\mathrm{Cu}$ surface. Cross-sectional images of the $\mathrm{Cu}$ films were obtained during etching, as shown in Fig. 5. In order to make the insulating PVA layer visible in the images, a thin $\mathrm{Au}$ layer was deposited by a simple sputtering process before SEM observation. Therefore, the dark areas in between the top Au layer and the $\mathrm{Cu}$ surface should be occupied mainly by PVA in the images. This is corroborated by the fact that the widths of the PVA (approximately $4 \mu \mathrm{m}$ ) are consistent with those in the top view image of the PVA line in Fig. 4(c). It can be seen that the PVA layer could stick to the $\mathrm{Cu}$ surface throughout the process. The 6 min etching process yielded $\mathrm{Cu}$ grid lines with a width of $3 \mu \mathrm{m}$ and a height of $0.8 \mu \mathrm{m}$ together with the PVA coating on all the exposed $\mathrm{Cu}$ surfaces (Fig. 4(f) and 5(c)). Surprisingly, the $\mathrm{Cu}$ height decreased from $1.2 \mu \mathrm{m}$ to $0.8 \mu \mathrm{m}$ after etching. We assume that this could be occurred by the penetration of $\mathrm{Fe}^{3+}$ through the PVA film for two reasons. Firstly, there is a dependence of the etching rate on the PVA film thickness. More aggressive $\mathrm{Cu}$ etching through a spin-coated PVA (thickness: about $200 \mathrm{~nm} v s$. ca. $1 \mu \mathrm{m}$ for the grid electrode) was observed. The $\mathrm{Cu}$ height under the PVA film became from $1.4 \mu \mathrm{m}$ to 0.4 $\mu \mathrm{m}$ when the bare $\mathrm{Cu}$ region was etched away. Secondly, there is no detached PVA film on the surface. The etching could proceed by the penetration of $\mathrm{Fe}^{3+}$ into the PVA layer to contact with the top of the $\mathrm{Cu}$ surface, rather than the penetration into the interface between the PVA film and the $\mathrm{Cu}$ surface from the edge. As for the undercut, it can also be mitigated by the PVA coating effect on the side, considering the long width as well as the square shape of the side wall of the $\mathrm{Cu}$ grid line. The undercut of the $\mathrm{Cu}$ did not proceed at the same rate as that of the bare $\mathrm{Cu}$ area (75 vs. $120 \mathrm{~mm} \mathrm{~min}^{-1}$ ) assuming that the PVA layer expanded to cover $4.5 \mu \mathrm{m}$ of the length. The undercut through the isotropic etching often causes a trapezoidal shape of the metal under the resist, because the closer the metal is to the resist, the more etchant can access the metal earlier. After the etching, the surface was sufficiently cleaned with methanol. There was no significant signal due to $\mathrm{Cl}$ on the exposed PEN area, according to the SEM-EDS analysis (Fig. 2S $\dagger$ ). This indicates that the etched $\mathrm{Cu}$ attained a form capable of being dissolved in methanol, such as $\mathrm{CuCl}_{2}$ rather than $\mathrm{CuCl}$, although no additional $\mathrm{Cl}$ source such as $\mathrm{HCl}$ was added. ${ }^{28} \mathrm{~A}$ very small signal of $\mathrm{Cl}$ and $\mathrm{Fe}$ was observed in the $\mathrm{Cu}$ line covered with PVA patterns (Fig. 3S $\dagger$ ). XPS spectra in the Fe (2p) region showed a small signal due to $\mathrm{Fe}(\mathrm{III})$ in the PVA coated $\mathrm{Cu}$ area (Fig. $2 \mathrm{~S} \dagger$ ). This might be a trace revealing some $\mathrm{FeCl}_{3}$ penetration into the PVA resist. A Cu grid transparent electrode $(6 \mathrm{~cm} \times 10 \mathrm{~cm})$ is shown in Fig. 4S. $\dagger$ A 5-6 min of etching time for the $\mathrm{Cu}$ thin films (thickness: 1-1.2 $\mu \mathrm{m}$ ) on PEN substrates yielded a sheet resistance of $6.1 \pm 5.3 \Omega \square^{-1}$ and transmittance of $87.2 \pm 5.2 \%$, averaged over 24 samples. Although there are some large deviations, the averaged parameters surpassed those of the conventional ITO (transmittance at $550 \mathrm{~nm}$ : 83\%, and sheet resistance: $10 \Omega \square^{-1}$ ) in general. Because PVA is well known as a packaging polymer to prevent oxygen transmittance, ${ }^{29,30}$ we examined the effect of the PVA film over the etched $\mathrm{Cu}$ in terms of oxidation resistance.

For comparison, etched $\mathrm{Cu}$ samples without PVA were prepared: the PVA was removed by soaking the etched $\mathrm{Cu}$ in water for $5 \mathrm{~h}$. The etched $\mathrm{Cu}$ samples with and without PVA coating were heated up to $150{ }^{\circ} \mathrm{C}$ to observe their oxidation
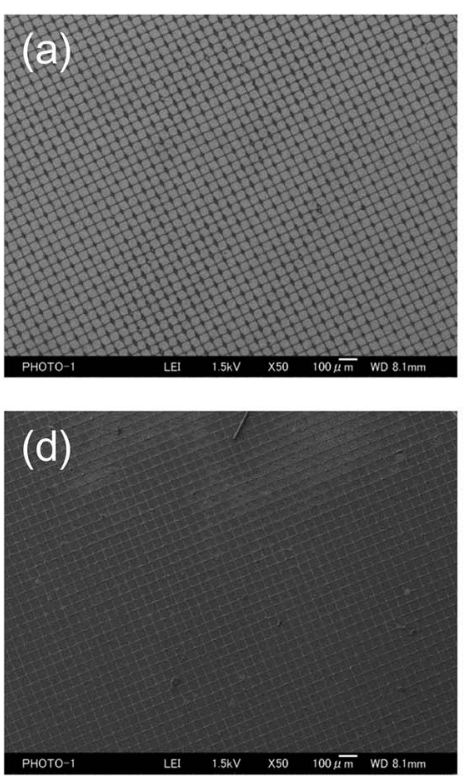
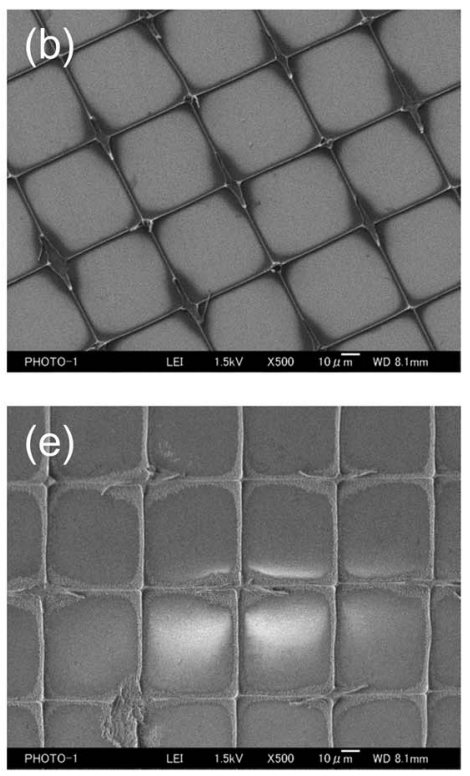
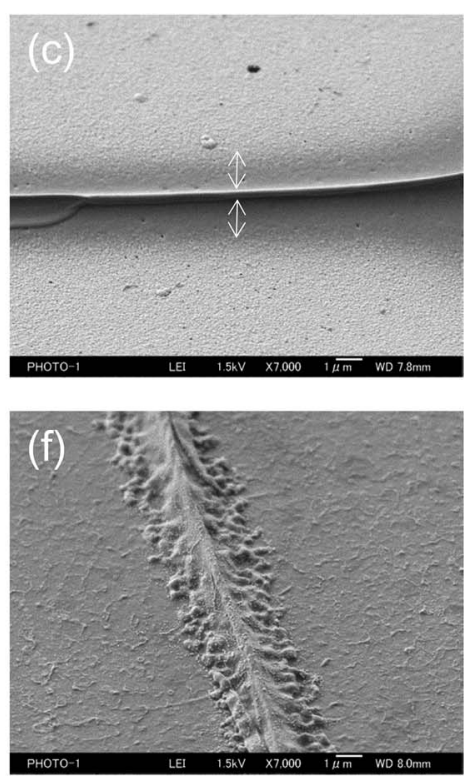

Fig. 4 SEM images of sputtered Cu surfaces before $(a-c)$ and after $(d-f)$ etched using a $0.01 \mathrm{M} \mathrm{FeCl}_{3}$ methanolic solution. 

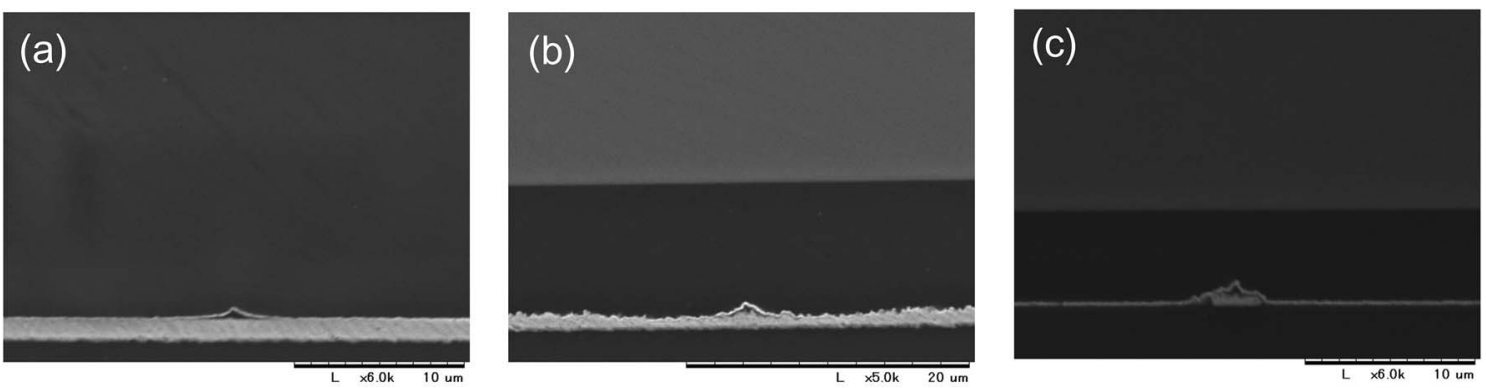

Fig. 5 Cross-sectional SEM images of Cu on PEN after (a) $0 \mathrm{~min}$, (b) $3 \mathrm{~min}$, and (c) 6 min etching.

resistance. As a result, the electric resistance of the sample without PVA increased significantly after $100 \mathrm{~min}$, whereas that of the sample with PVA did not change much, even after 230 min (Fig. 6). This shows that the PVA almost completely covered the etched $\mathrm{Cu}$ surface to prevent oxidation. At $200^{\circ} \mathrm{C}$ for less than $60 \mathrm{~min}$ the grid electrode without PVA became an insulator, whereas that with the polymer did not change significantly. X-ray photoelectron spectroscopy (XPS) results showed that the surface of the no-PVA $\mathrm{Cu}$ electrode was completely oxidized, whereas the PVA-covered $\mathrm{Cu}$ surface had the same XPS signals as before the heat treatment (Fig. 5S $\dagger$ ). These results revealed that the PVA-coated $\mathrm{Cu}$ surface has high oxidation resistance.

Finally, we applied the PVA-coated $\mathrm{Cu}$ grid electrodes for a capacitor sensor sensing pressure as a preliminary experiment. Basically, the whole sensor was fabricated just by putting two grid electrodes together so as to contact the both of PVA top layers as shown in the inset of Fig. 7. The PVA layers can serve as insulating layers. Therefore, the sensor is expected to detect the magnitude of the applied pressure by measuring the capacitance change $(\Delta C)$ generated in $\mathrm{Cu} / \mathrm{PVA} / \mathrm{Cu}$ stacked layers. Fig. 7 shows the capacitance changes as a function of applied pressure. For the pressures below $10 \mathrm{kPa}, \Delta C$ increases rapidly while $\Delta C$ increases in a gradually linear fashion for the pressures over 10

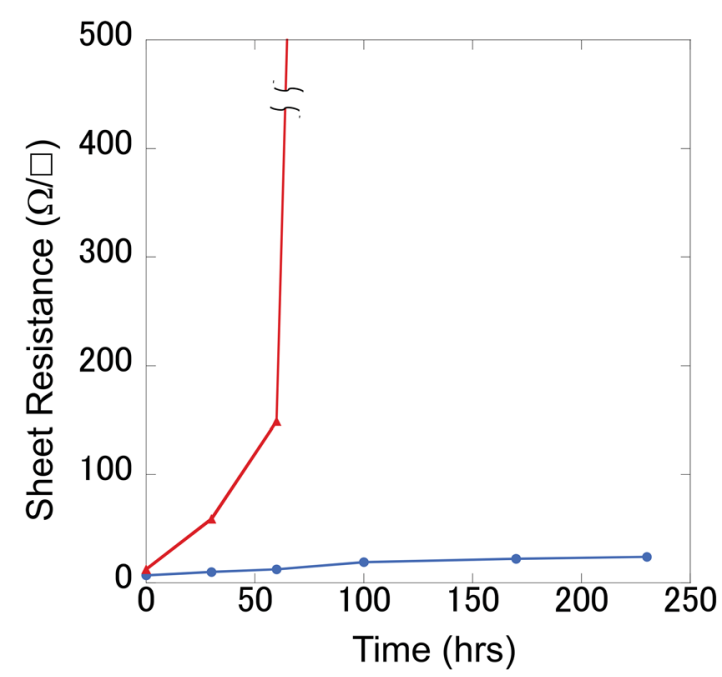

Fig. 6 Sheet resistance changes for grid $\mathrm{Cu}$ electrodes with $(O)$ and without $(\triangle)$ PVA upon heating at $150{ }^{\circ} \mathrm{C}$ in the atmosphere as a function of time.

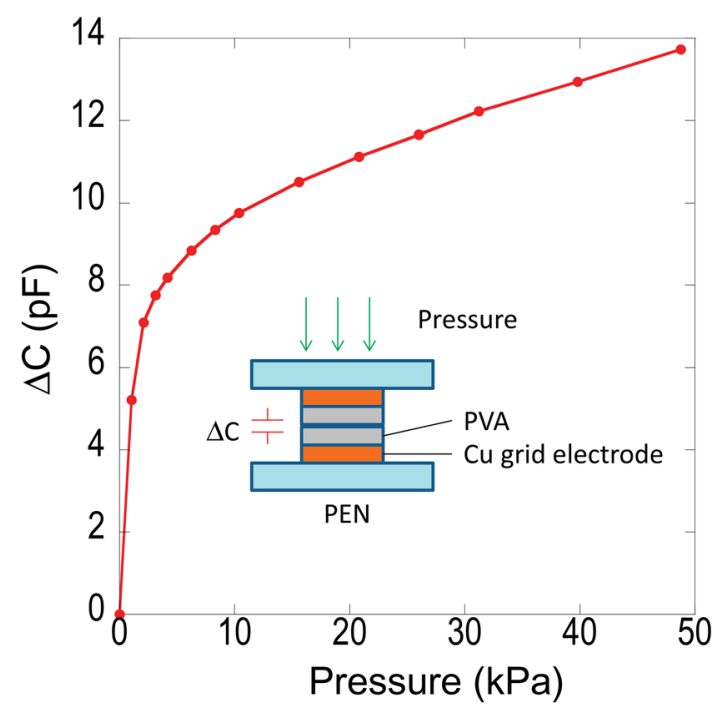

Fig. 7 Capacitance changes of the sensor made of grid Cu electrodes as a function of applied pressure.

$\mathrm{kPa}$. This result reveals that the PVA layers on $\mathrm{Cu}$ electrodes can work quite well as the insulating layer for the capacitor sensor.

\section{Conclusions}

A simple method to form a grid-pattern protecting layer on a $\mathrm{Cu}$ thin film was developed in order to obtain a transparent grid pattern by wet etching. It essentially relied on a capillary force generated between a screen mesh and the substrate when an aqueous solution containing a PVA-based polymer was introduced. The liquid bridges formed between the contacting points of the mesh and the substrate were stable enough to yield a fine-line network of solidified PVA-based polymers. A wetetching process using $\mathrm{FeCl}_{3}$ proceeded isotropically to obtain a Cu-grid pattern thoroughly coated in the PVA-based polymer. The resulting $\mathrm{Cu}$ grid electrode showed good transparency and sufficiently low resistance. The PVA-based polymer coating on the $\mathrm{Cu}$ grid pattern efficiently protected from the $\mathrm{Cu}$ oxidation. This can be a good passivation to avoid decrease in the transparency due to filling all the surfaces with a passivation layer and their degradation. A preliminary result demonstrated that the PVA-coated electrode could work as a capacitor sensor sensing pressure. 
Our method can be applied for nonflat surfaces, such as a cylindrical surface, because the screen mesh template is so flexible as to be easily conformable with the required surface.

\section{Conflicts of interest}

There are no conflicts to declare.

\section{Acknowledgements}

A part of this work was conducted at Tsukuba West and the Nano Processing Facility (NPF) of AIST.

\section{References}

1 X. Wang, L. Zhi, N. Tsao, Ž. Tomović, J. Li and K. Müllen, Angew. Chem., Int. Ed., 2008, 47, 2990-2992.

2 J. Zou, H.-L. Yip, S. K. Hau and A. K.-Y. Jen, Appl. Phys. Lett., 2010, 96, 203301.

3 G. Gu, V. B. A. P. E. Burrows, S. R. Forrest and M. E. Thompson, Appl. Phys. Lett., 1996, 68, 2606-2608.

4 K. Han-Ki, D. G. Kim, K. S. Lee, M. S. Huh, S. H. Jeong, K. I. Kim and S. Tae-Yeon, Appl. Phys. Lett., 2005, 86, 183503.

5 M. J. Kim, D. W. Shin, J.-Y. Kim, S. H. Park, I. t. Han and J. B. Yoo, Carbon, 2009, 47, 3461-3465.

6 P. Blake, P. D. Brimicombe, R. R. Nair, T. J. Booth, D. Jiang, F. Schedin, L. A. Ponomarenko, S. V. Morozov, H. F. Gleeson, E. W. Hill, A. K. Geim and K. S. Novoselov, Nano Lett., 2008, 8, 1704-1708.

7 S. Bae, H. Kim, Y. Lee, X. Xu, J.-S. Park, Y. Zheng, J. Balakrishnan, T. Lei, H. Ri Kim, Y. I. Song, Y.-J. Kim, K. S. Kim, B. Ozyilmaz, J.-H. Ahn, B. H. Hong and S. Iijima, Nat. Nanotechnol., 2010, 5, 574-578.

8 J. Wang, M. Liang, Y. Fang, T. Qiu, J. Zhang and L. Zhi, Adv. Mater., 2012, 24, 2874-2878.

9 D. S. Hecht, L. Hu and G. Irvin, Adv. Mater., 2011, 23, 14821513.

10 Z. Liu, J. Xu, D. Chen and G. Shen, Chem. Soc. Rev., 2015, 44, 161-192.

11 F. Di Giacomo, A. Fakharuddin, R. Jose and T. M. Brown, Energy Environ. Sci., 2016, 9, 3007-3035.
12 S. Ye, A. R. Rathmell, Z. Chen, I. E. Stewart and B. J. Wiley, Adv. Mater., 2014, 26, 6670-6687.

13 V. B. Nam and D. Lee, Nanomaterials, 2016, 6, 47.

14 J. C. Yun, Adv. Funct. Mater., 2017, 27, 1606641.

15 T. Sannicolo, M. Lagrange, A. Cabos, C. Celle, J.-P. Simonato and D. Bellet, Small, 2016, 12, 6052-6075.

16 M. Morales-Masis, S. De Wolf, R. Woods-Robinson, J. W. Ager and C. C. Ballif, Adv. Electron. Mater., 2017, 3, 1600529.

17 H. Jin, S. Jung, J. Kim, S. Heo, J. Lim, W. Park, H. Y. Chu, F. Bien and K. Park, Sci. Rep., 2017, 7, 10854.

18 K. Zilberberg and T. Riedl, J. Mater. Chem. A, 2016, 4, 1448114508.

19 A. R. Rathmell, S. M. Bergin, Y.-L. Hua, Z.-Y. Li and B. J. Wiley, Adv. Mater., 2010, 22, 3558-3563.

20 W.-K. Kim, S. Lee, D. Hee Lee, I. Hee Park, J. Seong Bae, T. Woo Lee, J.-Y. Kim, J. H. Park, Y. Cho, C. Cho and S.-Y. Jeong, Sci. Rep., 2015, 5, 10715.

21 J. H. Park, D. Y. Lee, Y.-H. Kim, J. K. Kim, J. H. Lee, J. H. Park, T.-W. Lee and J. H. Cho, ACS Appl. Mater. Interfaces, 2014, 6, 12380-12387.

22 T. He, A. Xie, D. H. Reneker and Y. Zhu, ACS Nano, 2014, 8, 4782-4789.

23 S. Yang, I. Kymissis, E. Leland, S. Liu and S. O'Brien, J. Vac. Sci. Technol., B: Microelectron. Nanometer Struct., 2013, 31, 060603.

$24 \mathrm{H}$. B. Huntington, Electromigration in Metals, in Diffusion in Solids, ed. A. S. Nowick and J. J. Burton, Academic Press, New York, 1975, ch. 6, pp. 303-352.

25 H. Tokuhisa, S. Tsukamoto, S. Morita, S. Ise, M. Tomita and N. Shirakawa, Appl. Surf. Sci., 2016, 400, 64-70.

26 I. U. Vakarelski, J. O. Marston and S. T. Thoroddsen, Langmuir, 2013, 29, 4966-4973.

27 I. U. Vakarelski, J. W. Kwek, X. Tang, S. J. O'Shea and D. Y. C. Chan, Langmuir, 2009, 25, 13311-13314.

28 Y. Xia, E. Kim, M. Mrksich and G. M. Whitesides, Chem. Mater., 1996, 8, 601-603.

29 M. Lim, H. Kwon, D. Kim, J. Seo, H. Han and S. B. Khan, Prog. Org. Coat., 2015, 85, 68-75.

30 M. Lim, D. Kim and J. Seo, Polym. Int., 2016, 65, 400-406. 